\title{
Graded oxygen saturation targets and retinopathy of prematurity in extremely preterm infants
}

\author{
Rowena Cayabyab ${ }^{1,2}$, Vasudha Arora ${ }^{3}$, Fiona Wertheimer ${ }^{1,2}$, Manuel Durand ${ }^{1,2}$ and Rangasamy Ramanathan ${ }^{1,2}$
}

BACKGROUND: We compared the incidence of severe retinopathy of prematurity (ROP) and need for laser treatment before and after implementing graded pulse oximeter oxygen saturation $\left(\mathrm{SpO}_{2}\right)$ targets in extremely preterm infants. Mortality and other secondary outcomes were compared.

METHODS: Before 2002, we used $90-94 \%$ as the $\mathrm{SpO}_{2}$ target in infants $24^{0 / 7}-27^{6 / 7}$ wk gestation and birth weight $<1,000 \mathrm{~g}$ until $35^{6 / 7}$ wk postmenstrual age (PMA). We implemented graded $\mathrm{SpO}_{2}$ targets based on vaso-obliterative and vaso-proliferative phases of ROP in 2002. Group 1 (1995-2001) before, and Group 2 (2003-2010) after implementation of graded $\mathrm{SpO}_{2}$ targets based on PMA (83-89\% until 326/7 wk, 90-94\% until $35^{6 / 7}$ wk and $>94 \%$ at $\geq 36$ wk PMA).

RESULTS: There were 267 patients in Group 1 and 220 in Group 2. There was no significant difference in birth weight or gestational age. Severe ROP (adjusted OR: 0.18, 95\% Cl: 0.11, $0.30 ; P<0.001$ ) and laser surgery rates (adjusted OR: 0.31, 95\% $\mathrm{Cl}: 0.18,0.52 ; P<0.001)$ decreased significantly in Group 2. There was no difference in mortality (adjusted OR: $0.74,95 \% \mathrm{Cl}$ : $0.37,1.49 ; P=0.40$ ).

CONCLUSION: In this retrospective cohort study, implementation of graded $\mathrm{SpO}_{2}$ targets decreased severe ROP and need for laser therapy, without increasing mortality.

$\mathbf{R}^{\mathrm{c}}$ etinopathy of prematurity (ROP) is a leading cause of blindness in premature neonates worldwide. As advances in neonatal medicine have improved the survival of extremely preterm infants, ROP continues to be a major cause of significant morbidity. Although there are several risk factors associated with the development of ROP, the role of supplemental oxygen with elevated arterial oxygen tension is believed to be a major risk factor (1-7). Vascular endothelial growth factor (VEGF), an oxygen dependent growth factor, has been known to play a significant role in the pathogenesis of ROP $(8,9)$. Nonoxygen-related growth factors, such as, insulin-like growth factor-1 (IGF-1) also interact with VEGF in the pathogenesis of ROP.

Two phases have been described in the pathogenesis of ROP (10). After preterm birth and from 22 to $\sim 32 \mathrm{wk}$ postmenstrual age (PMA), the key event in the phase I ROP is the process of vaso-obliteration. While fetal oxygen saturations are on the order of $50-60 \%$, the postnatal environment is relatively hyperoxic, with oxygen saturations of $80-100 \%$. This increased oxygen saturation results in decreased levels of hypoxia-inducible factor-1 (HIF-1), decreased VEGF secretion, and decreased angiogenesis. Hyperoxia associated with supplemental oxygen augments this downregulation of angiogenesis. New retinal blood vessel growth ceases and existing vessels constrict and retract.

Phase II ROP, namely, vaso-proliferative phase, which starts around $33 \mathrm{wk}$ PMA, is marked by abnormal vessel growth (10). Although angiogenesis is attenuated in phase I ROP, programmed development, proliferation, and differentiation of retinal neural cells continue, increasing retinal metabolic demands. Hypoxia of the peripheral avascular retina ensues and VEGF production is increased via HIF-1 acting as a transcription factor. Over production of VEGF is important in retinal neovascularization. Since preterm infants have low circulating tissue concentrations of IGF-1 initially, VEGF is unable to trigger angiogenesis, because endothelial cell response to VEGF is mediated via IGF-1. However, with advancing gestational age, tissue concentrations of IGF-1 increase and reach a critical threshold, allowing VEGF-mediated angiogenesis and rapid-onset, excessive aberrant vessel growth at the interface between the vascularized and avascularized retina. With inadequate oxygenation as with using low-oxygen saturation during this time window, extra retinal neovascularization continues and may result in hemorrhage, fibrous bands, macular dragging, and retinal detachment (9). Phase I ROP is clearly due to hyperoxia and phase II ROP is due to retinal hypoxia.

The optimal pulse oximeter oxygen saturation $\left(\mathrm{SpO}_{2}\right)$ target for preterm newborns remains controversial (11). To decrease the risk of ROP, many neonatal intensive care units (NICUs) targeted lower $\mathrm{SpO}_{2}$ in premature neonates receiving supplemental oxygen (12). Large randomized trials showed a reduction in severe ROP among survivors but increased mortality before discharge in extremely preterm infants when $\mathrm{SpO}_{2}$ target was limited to $85-89 \%$ as compared to $91-95 \%$ from birth to

\footnotetext{
'Division of Neonatal Medicine, LAC+USC Medical Center, Keck School of Medicine, University of Southern California, Los Angeles, California; ${ }^{2}$ Children's Hospital Los Angeles, Keck School of Medicine, University of Southern California, Los Angeles, California; ${ }^{3}$ Department of Pediatrics, Kaiser Foundation Hospitals, Downey, California. Correspondence: Rowena Cayabyab (cayabyab@usc.edu)

Received 24 November 2015; accepted 26 February 2016; advance online publication 11 May 2016. doi:10.1038/pr.2016.98
} 


\section{Articles Cayabyab et al.}

36 wk PMA $(13,14)$. However, another large randomized study did not show a difference in mortality or disability at 18 mo of age in infants assigned to saturations of $85-89$ vs. 91-95\% (15). Furthermore, there was no difference in ROP between the two groups, which might have been due to the higher median $\mathrm{SpO}_{2}$ (90.9\%) in the lower target group in the study (15).

We targeted $\mathrm{SpO}_{2}$ of 90-94\% from 1995-2001 in infants on supplemental oxygen with a birth weight $(\mathrm{BW})<1,000 \mathrm{~g}$ and $24^{0 / 7}-27^{6 / 7}$ wk gestation at birth until $35^{6 / 7}$ wk PMA. Once the infants reached a PMA of $\geq 36 \mathrm{wk}$, the $\mathrm{SpO}_{2}$ limits were liberalized to $>94 \%$. We changed our practice in 2002, when we adopted graded $\mathrm{SpO}_{2}$ targets for all patients with $\mathrm{BW}<1,000 \mathrm{~g}$, gestational age (GA) $24^{0 / 7}-27^{6 / 7} \mathrm{wk}$ at birth based on the two phases of ROP. For those patients $<33$ wk PMA, target oxygen saturations were $83-89 \%$ to prevent relative retinal hyperoxia during phase I of ROP (10). Once these patients reached a PMA of $\geq 33 \mathrm{wk}$, their target oxygen saturations were liberalized to $90-94 \%$ to prevent retinal hypoxia. This corresponded to phase II of ROP (10). When these patients reached $\geq 36 \mathrm{wk}$ PMA, their $\mathrm{SpO}_{2}$ was further liberalized to > 94\% (Table 1). The objective of our study was to compare the incidence of severe ROP and need for laser treatment before and after the adoption of graded $\mathrm{SpO}_{2}$ targets in extremely preterm infants. Death before hospital discharge and other secondary outcomes were also compared. We hypothesized that using graded $\mathrm{SpO}_{2}$

Table 1. Oxygen saturation targets during the 2 study time periods

\begin{tabular}{lcc}
\hline & \multicolumn{2}{c}{ Oxygen saturation targets } \\
\cline { 2 - 3 } PMA & $1995-2001$ & $2003-2010$ \\
\hline Until 32 $2^{6 / 7}$ wk PMA & $90-94 \%$ & $83-89 \%$ \\
At 33-35/7 wk PMA & $90-94 \%$ & $90-94 \%$ \\
At 36 $36^{0 / 7}$ wk PMA & $>94 \%$ & $>94 \%$
\end{tabular}

PMA, postmenstrual age. targets in extremely preterm infants would decrease the incidence of severe ROP without an increase in mortality when compared to using static $\mathrm{SpO}_{2}(90-94 \%)$ target.

\section{RESULTS}

A total of 739 patients born between $24^{0 / 7}$ and $27^{6 / 7}$ wk and with a $\mathrm{BW}<1,000 \mathrm{~g}$ were admitted in the two NICUs from 1995 to 2010. Fifty-three neonates admitted during 2002 were excluded because 2002 was a transitional year. In addition, 97 patients were excluded from Group 1 and 102 patients were excluded from Group 2. A total of 487 patients comprised our study population (Figure 1). There were 267 patients in Group 1 (1995-2001) and 220 patients in Group 2 (20032010). BW (mean \pm SD, $747 \mathrm{~g} \pm 126$ vs. $724 \mathrm{~g} \pm 143, P=0.07$ ) and GA (25.6wk \pm 1.1 vs. $25.7 \mathrm{wk} \pm 1.1, P=0.16)$ as well as race, gender, multiple gestation, and other maternal/ neonatal variables were not significantly different between the two groups. However, the use of prenatal steroids (71.5 vs. $83.5 \%$, $P=0.002)$ and surfactant $(63.7$ vs. $90.6 \%, P<0.001)$ were significantly higher in Group 2 compared to Group 1 (Table 2).

After logistic regression analysis of the outcome measures to adjust for important covariates (BW, GA, multiple gestation indicator, hospital of birth, prenatal steroids, surfactant therapy, gender, and race), there was a significant reduction in the incidence of severe ROP ( 48.3 vs. $21.3 \%$, adjusted odds ratio (OR): $0.18,95 \%$ CI: $0.11,0.30 ; P<0.001)$ and need for laser surgery (34.9 vs. $19.7 \%$, adjusted OR: $0.31,95 \%$ CI: $0.18,0.52$; $P<0.001$ ) in Group 2 compared to Group 1 (Table 3).

There was no significant difference in mortality before discharge between the two time periods. The incidence of bronchopulmonary dysplasia (BPD) was significantly lower and there was a slightly lower incidence of severe intraventricular hemorrhage in Group 2 when compared to Group 1, but no difference in the rate of necrotizing enterocolitis or patent ductus arteriosus between the two groups (Table 4).

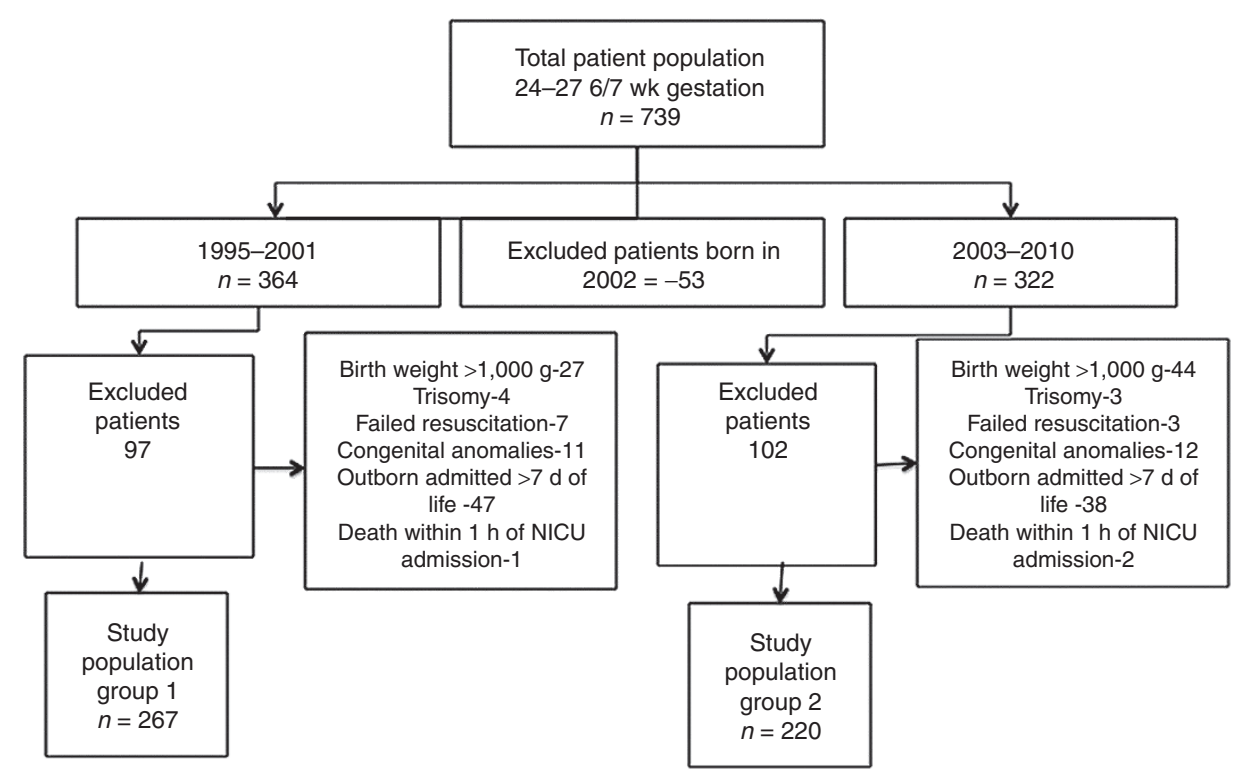

Figure 1. Outline of the study population. 


\section{DISCUSSION}

The primary goal of our study was to evaluate the incidence of severe ROP before and after adoption of graded $\mathrm{SpO}_{2}$ targets in extremely preterm infants. We show decreased rates of severe ROP and laser treatment with the use of graded oxygen saturation targets (Group 2) when compared to static saturation targets (Group 1). One alternative hypothesis for this improved outcome could be improved adherence or compliance by the respiratory, nursing and medical staff to target oxygen saturations in these infants secondary to better education and careful attention to the $\mathrm{SpO}_{2}$. We have reported improved outcomes

Table 2. Maternal and neonatal demographics

\begin{tabular}{|c|c|c|c|}
\hline & $\begin{array}{c}\text { Group 1, } \\
\text { 1995-2001, } \\
\text { Static } \mathrm{SpO}_{2}\end{array}$ & $\begin{array}{c}\text { Group 2, } \\
\text { 2003-2010, } \\
\text { Graded } \mathrm{SpO}_{2}\end{array}$ & \\
\hline & $n=267$ & $n=220$ & $P$ value \\
\hline Birth weight $(\mathrm{g})^{\mathrm{a}}$ & $747 \pm 126$ & $724 \pm 143$ & 0.07 \\
\hline Gestational age (weeks) ${ }^{\mathrm{a}}$ & $25.6 \pm 1.1$ & $25.7 \pm 1.1$ & 0.16 \\
\hline Female gender (\%) & $126 / 267(47.2)$ & $109 / 220(49.5)$ & 0.61 \\
\hline Race-Hispanic (\%) & $181 / 267(67.8)$ & $142 / 220(64.5)$ & 0.45 \\
\hline Maternal age (years) ${ }^{a}$ & $28.6 \pm 7.2$ & $29.0 \pm 7.5$ & 0.56 \\
\hline Multiple gestation (\%) & $42 / 267(15.7)$ & $28 / 220(12.7)$ & 0.35 \\
\hline Prenatal steroids (\%) & $188 / 263(71.5)$ & $182 / 218(83.5)$ & 0.002 \\
\hline $\mathrm{ROM}>12 \mathrm{~h}(\%)$ & $71 / 237(30.0)$ & $48 / 204(23.5)$ & 0.13 \\
\hline Maternal infection (\%) & $57 / 264(21.6)$ & $54 / 218(24.8)$ & 0.41 \\
\hline C-section (\%) & $185 / 264(70.1)$ & $163 / 219(74.4)$ & 0.29 \\
\hline Mechanical ventilation (d) & $39.0 \pm 23.6$ & $35.9 \pm 33.8$ & 0.25 \\
\hline Surfactant (\%) & $170 / 267(63.7)$ & 193/213 (90.6) & $<0.001$ \\
\hline Inotrope use (\%) & 238/267 (89.1) & $202 / 220(91.8)$ & 0.32 \\
\hline
\end{tabular}

after implementing potentially better practices such as use of lower oxygen saturations in our NICU $(16,17)$. In addition, there was no difference in mortality between the two groups, and there was a lower incidence of BPD with the use of graded $\mathrm{SpO}_{2}$ targets.

The incidence of severe ROP in our study is higher than previously reported in other randomized studies. However, our criteria for severe ROP included all patients with Stage III or higher (with or without plus disease), whereas in the Canadian Oxygen Trial only patients with Stage IV or V were included (15) and in the SUPPORT study only patients with threshold disease were included in the criteria for severe ROP (13). We included all infants with Stage III ROP because of its effect on visual acuity. Very-low-birth-weight infants with Stage III ROP had significantly lower visual acuity scores compared to infants with Stage I-II at 18-24 mo follow up. The visual acuity score improved at 36 mo for infants with Stage III ROP but still lagged behind those infants with Stage I-II (18). Our patients were also less than $26 \mathrm{wk}$ gestation on average and their birth weight was about $100 \mathrm{~g}$ less than the patients in the other studies. As reported by other investigators, intrauterine growth restriction is also a risk factor for severe ROP (19). Furthermore, survival at discharge was higher in our extremely preterm population compared with other trials accounting for more survivors, hence higher rate of morbidities.

Appropriate oxygen saturation target for preterm neonates is still a matter of debate. In the 1950s, it was discovered that high oxygen use led to ROP and blindness (1). With the use of lower amounts of oxygen and as the $40 \%$ rule came into effect, there was an increased incidence of early mortality and poor neurodevelopmental outcome associated with curtailed oxygen use $(20,21)$. Since then, $\mathrm{SpO}_{2}$ targets have been based on available clinical evidence $(22,23)$. To help resolve the uncertainty of how to titrate oxygen therapy in preterm infants $<28 \mathrm{wk} \mathrm{GA}$, five large randomized trials were designed with the primary outcome of

Table 3. Primary outcomes

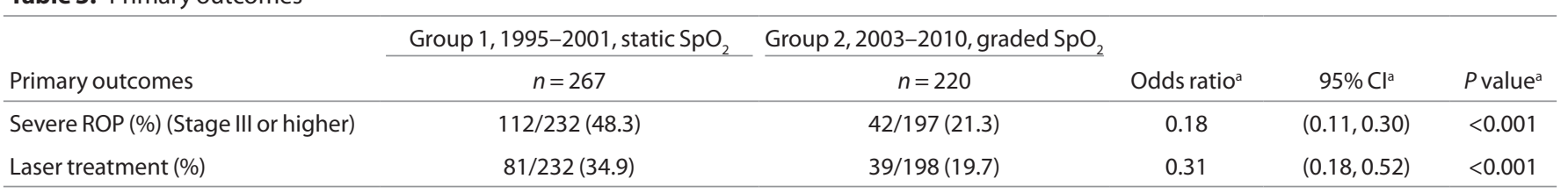

${ }^{a}$ Adjusted using logistic regression analysis.

$\mathrm{ROP}$, retinopathy of prematurity; $\mathrm{SpO}_{2^{\prime}}$ pulse oximeter oxygen saturation.

Table 4. Secondary clinical outcomes

\begin{tabular}{|c|c|c|c|c|c|}
\hline Clinical outcomes & $\begin{array}{c}\text { Group 1, 1995-2001, static } \mathrm{SpO}_{2} \\
n=267\end{array}$ & $\begin{array}{c}\text { Group 2, 2003-2010, graded } \mathrm{SpO}_{2} \\
n=220\end{array}$ & Odds ratio ${ }^{\mathrm{a}}$ & $95 \% \mathrm{Cl}^{\mathrm{a}}$ & $P$ value \\
\hline Death $^{b}(\%)$ & $28 / 243(11.5)$ & $22 / 217(10.1)$ & 0.74 & $(0.37,1.49)$ & 0.40 \\
\hline Necrotizing enterocolitis (\%) & $37 / 267(13.9)$ & $16 / 218(7.3)$ & 0.57 & $(0.29,1.10)$ & 0.09 \\
\hline Severe IVH (Grade III-IV) (\%) & $56 / 233(24.0)$ & $33 / 219(15.1)$ & 0.58 & $(0.34,0.99)$ & 0.047 \\
\hline
\end{tabular}

${ }^{a}$ Adjusted using logistic regression analysis. ${ }^{b}$ Death before discharge.

$\mathrm{IVH}$, intraventricular hemorrhage; $\mathrm{SpO}_{2^{\prime}}$ pulse oximeter oxygen saturation. 


\section{Articles | Cayabyab et al.}

death or neurodevelopmental impairment at 18 mo to $2 \mathrm{y}$ of age $(13-15,24,25)$. There were two $\mathrm{SpO}_{2}$ targets, $85-89$ or $91-95 \%$ in these preterm infants who were enrolled within $24 \mathrm{~h}$ of age, until they reached $36 \mathrm{wk}$ PMA. The SUPPORT trial showed decreased rates of severe ROP but increased mortality before discharge in the lower $\mathrm{SpO}_{2}$ target of $85-89$ vs. 91-95\% (13); however, there was no significant difference in the composite outcome of death or neurodevelopmental impairment but an increased rate of death at $18-22$ mo in the lower $\mathrm{SpO}_{2}$ target group (24). The BOOST II trial was halted because an interim analysis showed that survival at $36 \mathrm{wk}$ PMA was higher with the higher oxygen saturation target (14). However, 2-y outcomes did not show a significant effect on the rate of death or disability (New Zealand Collaborative Group) (25). On the other hand, the Canadian Oxygen Trial did not show an increase in mortality or disability at 18 mo with the lower $\mathrm{SpO}_{2}$ target of 85-89\% compared with 91-95\% (15). While some randomized trials suggest not targeting $\mathrm{SpO}_{2}$ less than $90 \%(13,14)$, one trial found it prudent to target $\mathrm{SpO}_{2}$ at $85-95 \%$ while strictly enforcing alarm limits of 85 and $95 \%$ at all times of oxygen therapy (15). Systematic review and meta-analysis of the above trials in extremely preterm infants have been reported $(26,27)$. One showed an increased mortality but reduced severe ROP with the lower $\mathrm{SpO}_{2}$ target (85-89\%) and suggested that $\mathrm{SpO}_{2}$ should be targeted at $90-95 \%$ until 36 wk PMA (26). The other meta-analysis incorporated the Grades of Recommendation, Assessment, Development, and Evaluation criteria and showed that the quality of the evidence is low for the estimate of effect of lower mortality before discharge with the higher $\mathrm{SpO}_{2}$ target (91-95\%), and suggested that oxygen saturations between 85 and $95 \%$ remain acceptable $(27,28)$. After reviewing the evidence from the above-randomized trials, a single center published their rates of ROP after changing their $\mathrm{SpO}_{2}$ targets from $88-92$ to $91-95 \%$ for preterm infants $<30 \mathrm{wk}$ GA (29). Their study showed that the rate and severity of ROP increased especially amongst extremely preterm infants after adopting a higher $\mathrm{SpO}_{2}$ target (91-95\%) with no concomitant reduction in mortality but the study was underpowered for this outcome (29).

Based on the pathophysiology of ROP, studies were designed to address the issue of using a higher $\mathrm{SpO}_{2}$ target at $32 \mathrm{wk}$ PMA which resulted in reduced progression to severe ROP (30). We implemented graded $\mathrm{SpO}_{2}$ targets in 2002, mimicking oxygen delivery: oxygen consumption ratios during fetal life. With the use of graded $\mathrm{SpO}_{2}$ targets oxygen delivery is increased around 33 wk PMA and minimizes relative hypoxia to the maturing retina. It is possible that a static high or low oxygen saturation target may not be the ideal $\mathrm{SpO}_{2}$ target for a disease with vasoobliterative and vaso-proliferative phases.

To our knowledge, our study is the first to report the use of graded $\mathrm{SpO}_{2}$ targets in neonates less than $28 \mathrm{wk}$ gestation $\left(24^{0 / 7}-27^{6 / 7} \mathrm{wk}\right)$ and $<1,000 \mathrm{~g}$ at birth in relation to outcomes. The decreased incidence of severe ROP, need for laser treatment, and $\mathrm{BPD}$ with graded $\mathrm{SpO}_{2}$ targets is consistent with the results of other studies using a lower $\mathrm{SpO}_{2}$ target (13). Exposure to supplemental oxygen in the premature developing lung is a major factor contributing to the development of
BPD $(31,32)$. It is possible that use of initial lower $\mathrm{SpO}_{2}$ targets and later higher $\mathrm{SpO}_{2}$ targets protects the lung from the hyperoxia induced injury and production of cytotoxic reactive oxygen species during the early stages of lung development. We did not observe a significant change in mortality; however the sample size in our study is smaller than in other large randomized studies (13-15). It is known that the retinal oxygen demands increase around $33 \mathrm{wk}$ PMA (10); therefore it is likely that there might be an overall increase in body's oxygen demand around this time and that similar benefit might be seen with increase in $\mathrm{SpO}_{2}$ targets on other organ systems. The increased oxygen delivery might prevent progression of disease processes like pulmonary hypertension that may predispose the extremely preterm infants to death.

Our study is also limited by its retrospective nature. As we used historical controls for our graded $\mathrm{SpO}_{2}$ target population, there is an indeterminate element of contribution from changes in clinical practice over time. We did account for several important confounding variables including the increased use of prenatal steroids and surfactant in the graded $\mathrm{SpO}_{2}$ group in our study, but other small changes may not be accounted for. The use of surfactant was higher in the graded $\mathrm{SpO}_{2}$ group because all babies less than $29 \mathrm{wk}$ were routinely intubated for surfactant administration and extubated (INSURE) to noninvasive positive pressure ventilation. This was a change in practice on the use of surfactant for both institutions starting in 2002. We did not specify any $\mathrm{FiO}_{2}$ and/or $\mathrm{SpO}_{2}$ as a requirement for surfactant administration. The same group of neonatologists practiced at both hospitals, which made deviations from our best practice guidelines less likely. We did not have a documentation of continuous $\mathrm{SpO}_{2}$ monitoring to determine the percent of or actual time the patients spent in the desired oxygen saturation targets. However, we have previously shown improved outcomes after implementing potentially better practices such as use of lower oxygen saturations in our NICU $(16,17)$. Data on neurodevelopmental outcomes in our patients are likewise not reported in this study.

\section{Conclusion}

Our findings indicate that there was a significant decrease in severe ROP (Stage III or higher) and laser treatment with the use of graded $\mathrm{SpO}_{2}$ targets based on the two different phases of ROP with advancing gestational age in extremely preterm infants. BPD also decreased and there was no increase in mortality before hospital discharge with the implementation of graded $\mathrm{SpO}_{2}$ targets. Use of either a high or low static $\mathrm{SpO}_{2}$ target for a disease with two distinct phases may not be the best approach. Randomized trials are needed to validate the use of graded $\mathrm{SpO}_{2}$ targets to decrease severe ROP, without increasing mortality or adverse long-term neurodevelopmental outcomes in extremely preterm infants.

\section{METHODS}

\section{Study Design}

Our study population consisted of neonates admitted to the NICU in two University of Southern California affiliated hospitals: Los Angeles County+University of Southern California Medical Center (52.4\%) and Good Samaritan Hospital (47.6\% of the study population). The 
same group of neonatologists staffed both NICUs. The Institutional Review Board from LAC+USC Medical Center and Good Samaritan Hospital approved the study. Informed consent was waived due to the retrospective nature of the study.

Extremely preterm infants born during the two study periods with GA between $24^{0 / 7}$ and $27^{6 / 7} \mathrm{wk}$ and $\mathrm{BW}<1,000 \mathrm{~g}$ were included in the study. Two time periods were compared: Group 1 (time period 1: 1 January 1995 to 31 December 2001) where we used static $\mathrm{SpO}_{2}$ target (90-94\%) till 356/7 wk PMA and Group 2 (time period 2: 1 January 2003 to 31 December 2010) where we used graded $\mathrm{SpO}_{2}$ targets. Exclusion criteria were: (i) neonates born in 2002 as that was a transitional year, (ii) $\mathrm{BW} \geq 1,000 \mathrm{~g}$, (iii) failed resuscitation in delivery room or demise within the first hour of NICU admission, (iv) complex congenital heart disease, (v) other major congenital anomalies/chromosomal abnormalities, and (vi) outborn patients admitted beyond the first week of life.

Primary outcomes were the incidence of severe ROP and need for laser treatment in the two time periods. Secondary outcomes included death before hospital discharge and the incidence of BPD, necrotizing enterocolitis, severe intraventricular hemorrhage, and patent ductus arteriosus in the two time periods.

\section{Measurements/Data Collection}

Measurements of $\mathrm{SpO}_{2}$, with the use of pulse oximeter were performed and recorded as part of standard of care for every admission in both NICUs. The fraction of inspired oxygen concentration $\left(\mathrm{FiO}_{2}\right)$ was adjusted based on the target $\mathrm{SpO}_{2}$ readings. Extensive in-service to all the NICU staff on the target oxygen saturations (Table 1), and guidelines for monitoring and adjustment of $\mathrm{FiO}_{2}$ was given (23). These guidelines were used during our previous study of physiologic reduced oxygen protocol (PROP) in three NICUs including Good Samaritan Hospital (16). This observational study showed decreased incidence of threshold ROP from 7.3 to $1.3 \%$. This significant reduction of threshold disease after implementation of PROP was a result of adherence to the guidelines. In our current study, there were no routine audits performed but the previous 24-h histogram of pulse oximeter readings from the bedside monitors were reviewed with nursing and respiratory staff during daily clinical rounds. Multiple members of the NICU team were responsible for ensuring that the patients remain in target oxygen saturations. Printed cards with $\mathrm{SpO}_{2}$ targets were placed at the bedside and were updated weekly to account for any changes in target oxygen saturation limits based on PMA (Table 1). Often, parents reminded or asked questions about the $\mathrm{SpO}_{2} \mathrm{~s}$, which helped our staff to comply with our target ranges. The NICU care was based on the best practices prevalent during the two time periods.

All data were extracted from our neonatal database (Neonatal Information System, NIS 3 and 5, Medical Data Systems, Rosemont, PA). These data were recorded prospectively on all patients admitted to both NICUs on a daily basis. Prenatal and perinatal demographic and clinical data including maternal demographics, maternal illnesses during pregnancy and labor, prenatal as well as labor medications, use of antenatal steroids, and mode of delivery were extracted. Neonatal variables included Apgar scores, surfactant treatment, ventilator days, exposure to vasopressors/inotropes, presence of severe ROP and its treatment, death, and occurrence of BPD, necrotizing enterocolitis, severe intraventricular hemorrhage, and patent ductus arteriosus.

A pediatric ophthalmologist examined our patients for ROP at $4 \mathrm{wk}$ of postnatal life or at $31 \mathrm{wk}$ PMA, whichever came later. Severe ROP was defined as Stage III or higher (with or without plus disease) and laser treatment was performed based on the revised indications for the treatment of ROP and upon the discretion of the attending pediatric ophthalmologist (33). BPD was defined as the use of supplemental oxygen at $36 \mathrm{wk}$ PMA (31). A diagnosis of necrotizing enterocolitis was made if Bell Stage II or higher was recorded $(34,35)$. Severe intraventricular hemorrhage (grade III-IV) was recorded according to the Papile grading system (36). Diagnosis of patent ductus arteriosus was made by serial echocardiography.

\section{Data Analysis}

Categorical variables were compared between the two groups (two time periods) by using the Chi-Square test or Fisher's exact test where appropriate. Continuous variables were compared by two-tailed, Student's $t$-tests for independent samples or Mann-Whitney $U$-test where appropriate (data not normally distributed). In addition, logistic regression models were developed to determine the independent risk of time period 2 (2003-2010) vs. time period 1 (1995-2001) for severe ROP and other outcomes. Logistic regression analysis included adjustment for the following covariates: birth weight, gestational age, multiple gestation, and hospital of birth, use of prenatal steroids, surfactant therapy, gender, and race. Data were analyzed using SPSS for Windows, version 16, Chicago, IL and SAS, version 9.2, Cary, NC. A $P$ value $<0.05$ was considered statistically significant for all tests.

\section{ACKNOWLEDGMENT}

We thank the neonatologists, neonatal fellows, and the staff of the neonatal intensive care units at LAC+USC Medical Center and Good Samaritan Hospital for their cooperation with the study.

\section{STATEMENT OF FINANCIAL SUPPORT \\ No funding was secured for this study.}

Disclosures: The authors have no financial relationships relevant to this article to disclose.

\section{REFERENCES}

1. Bedrossian RH, Carmichael P, Ritter J. Retinopathy of prematurity (retrolental fibroplasia) and oxygen. I. Clinical study. II. Further observations on the disease. Am J Ophthalmol 1954;37:78-86.

2. Gaynon MW, Stevenson DK, Sunshine P, Fleisher BE, Landers MB. Supplemental oxygen may decrease progression of prethreshold disease to threshold retinopathy of prematurity. J Perinatol 1997;17:434-8.

3. Kinsey VE, Arnold HJ, Kalina RE, et al. PaO2 levels and retrolental fibroplasia: a report of the cooperative study. Pediatrics 1977;60:655-68.

4. Phelps DL. Reduced severity of oxygen-induced retinopathy in kittens recovered in 28\% oxygen. Pediatr Res 1988;24:106-9.

5. Stuart MJ, Phelps DL, Setty BN. Changes in oxygen tension and effects on cyclooxygenase metabolites: III. Decrease of retinal prostacyclin in kittens exposed to hyperoxia. Pediatrics 1988;82:367-72.

6. Patz A, Hoeck LE, De La Cruz E. Studies on the effect of high oxygen administration in retrolental fibroplasia. I. Nursery observations. Am J Ophthalmol 1952;35:1248-53.

7. Flynn JT, Bancalari E, Snyder ES, et al. A cohort study of transcutaneous oxygen tension and the incidence and severity of retinopathy of prematurity. N Engl J Med 1992;326:1050-4.

8. Pierce EA, Foley ED, Smith LE. Regulation of vascular endothelial growth factor by oxygen in a model of retinopathy of prematurity. Arch Ophthalmol 1996;114:1219-28.

9. Robbins SG, Rajaratnam VS, Penn JS. Evidence for upregulation and redistribution of vascular endothelial growth factor (VEGF) receptors flt-1 and flk-1 in the oxygen-injured rat retina. Growth Factors 1998;16:1-9.

10. Smith LE. Pathogenesis of retinopathy of prematurity. Growth Horm IGF Res 2004;14 Suppl A:S140-4.

11. Higgins RD, Bancalari E, Willinger M, Raju TN. Executive summary of the workshop on oxygen in neonatal therapies: controversies and opportunities for research. Pediatrics 2007;119:790-6.

12. Anderson CG, Benitz WE, Madan A. Retinopathy of prematurity and pulse oximetry: a national survey of recent practices. J Perinatol 2004;24:164-8.

13. SUPPORT Study Group of the Eunice Kennedy Shriver NICHD Neonatal Research Network, Carlo WA, Finer NN, Walsh MC, et al. Target ranges of oxygen saturation in extremely preterm infants. N Engl J Med 2010; 362:1959-1969.

14. The BOOST II United Kingdom, Australia, and New Zealand Collaborative Groups. Oxygen saturation and outcomes in preterm infants. N Engl J Med 2013; 368:2094-2104.

15. Schmidt B, Whyte RK, Asztalos EV, et al.; Canadian Oxygen Trial (COT) Group. Effects of targeting higher vs lower arterial oxygen saturations on death or disability in extremely preterm infants: a randomized clinical trial. JAMA 2013;309:2111-20.

16. Wright KW, Sami D, Thompson L, Ramanathan R, Joseph R, Farzavandi S. A physiologic reduced oxygen protocol decreases the incidence of thresh- 


\section{Articles | Cayabyab et al.}

old retinopathy of prematurity. Trans Am Ophthalmol Soc 2006;104: $78-84$.

17. Noori S, Patel D, Friedlich P, Siassi B, Seri I, Ramanathan R. Effects of low oxygen saturation limits on the ductus arteriosus in extremely low birth weight infants. J Perinatol 2009;29:553-7.

18. Dogru M, Shirabe H, Nakamura M, Taoka K, Nomura K, Yamamoto M. Effect of retinopathy of prematurity on resolution acuity development in 1- to 3-year-old children. J Pediatr Ophthalmol Strabismus 2001;38:144-8.

19. Darlow BA, Hutchinson JL, Henderson-Smart DJ, Donoghue DA, Simpson JM, Evans NJ; Australian and New Zealand Neonatal Network. Prenatal risk factors for severe retinopathy of prematurity among very preterm infants of the Australian and New Zealand Neonatal Network. Pediatrics 2005;115:990-6.

20. James S, Lanman JT. History of oxygen therapy and retrolental fibroplasia. Prepared by the American Academy of Pediatrics, Committee on Fetus and Newborn with the collaboration of special consultants. Pediatrics 1976;57(suppl 2):591-642.

21. Bolton DP, Cross KW. Further observations on cost of preventing retrolental fibroplasia. Lancet 1974;1:445-8.

22. Tin W, Milligan DW, Pennefather P, Hey E. Pulse oximetry, severe retinopathy, and outcome at one year in babies of less than 28 weeks gestation. Arch Dis Child Fetal Neonatal Ed 2001;84:F106-10.

23. Chow LC, Wright KW, Sola A; CSMC Oxygen Administration Study Group. Can changes in clinical practice decrease the incidence of severe retinopathy of prematurity in very low birth weight infants? Pediatrics 2003;111:339-45.

24. Vaucher YE, Peralta-Carcelen M, Finer NN, et al.; SUPPORT Study Group of the Eunice Kennedy Shriver NICHD Neonatal Research Network. Neurodevelopmental outcomes in the early CPAP and pulse oximetry trial. N Engl J Med 2012;367:2495-504.

25. Darlow BA, Marschner SL, Donoghoe M, et al.; Benefits Of Oxygen Saturation Targeting-New Zealand (BOOST-NZ) Collaborative Group. Ran- domized controlled trial of oxygen saturation targets in very preterm infants: two year outcomes. J Pediatr 2014;165:30-35.

26. Saugstad OD, Aune D. Optimal oxygenation of extremely low birth weight infants: a meta-analysis and systematic review of the oxygen saturation target studies. Neonatology 2014;105:55-63.

27. Manja V, Lakshminrusimha S, Cook DJ. Oxygen saturation target range for extremely preterm infants: a systematic review and meta-analysis. JAMA Pediatr 2015;169:332-40.

28. Synnes A, Miller SP. Oxygen therapy for preterm neonates: the elusive optimal target. JAMA Pediatr 2015;169:311-3.

29. Manley BJ, Kuschel CA, Elder JE, Doyle LW, Davis PG. Higher rates of retinopathy of prematurity after increasing oxygen saturation targets for very preterm infants: experience in a single center. J Pediatr 2016;168:242-4.

30. Chen ML, Guo L, Smith LE, Dammann CE, Dammann O. High or low oxygen saturation and severe retinopathy of prematurity: a meta-analysis. Pediatrics 2010;125:e1483-92.

31. Jobe AH, Bancalari E. Bronchopulmonary dysplasia. Am J Respir Crit Care Med 2001;163:1723-9.

32. Buczynski BW, Maduekwe ET, O'Reilly MA. The role of hyperoxia in the pathogenesis of experimental BPD. Semin Perinatol 2013;37:69-78.

33. Early Treatment for Retinopathy of Prematurity Cooperative Group. Revised indications for the treatment of retinopathy of prematurity: results of the early treatment for retinopathy of prematurity randomized trial. Arch Ophthalmol 2003; 121:1684-1694.

34. Bell MJ, Ternberg JL, Feigin RD, et al. Neonatal necrotizing enterocolitis. Therapeutic decisions based upon clinical staging. Ann Surg 1978; 187:1-7.

35. Neu J. Necrotizing enterocolitis: the search for a unifying pathogenic theory leading to prevention. Pediatr Clin North Am 1996;43:409-32.

36. Papile LA, Burstein J, Burstein R, Koffler H. Incidence and evolution of subependymal and intraventricular hemorrhage: a study of infants with birth weights less than 1,500 gm. J Pediatr 1978;92:529-34. 